\title{
Mathematical model parameter estimation of a generating unit operating in the Polish National Power System
}

\author{
Ł. MAJKA* and S. PASZEK \\ Institute of Electrical Engineering and Computer Science, Silesian University of Technology, \\ 10 Akademicka St., 44-100 Gliwice, Poland
}

\begin{abstract}
In the paper, a method and results of parameter estimation of the mathematical model of a generating unit operating in the Polish National Power System are presented. Computations of the parameters were carried out based on measurement and simulation of dynamic waveforms of selected quantities of the generating unit. The problem of parameter identification was brought to minimization of the objective function determined by the vector of deviations between the approximated and approximating waveforms computed on the basis of the models expressed by the searched parameters. A hybrid optimization algorithm, being a serial combination of genetic and gradient algorithms, was used for minimization of the objective function. A methodology for filtering the recorded measurement signals is proposed in the paper. Method and results calculation of the sensitivity to changes of the model parameters of selected dynamic waveforms are also presented.
\end{abstract}

Key words: power system, generating unit, optimization, study of dynamic models.

\section{Introduction}

To minimize risks and reduce the occurrence of system failures resulting in the lack of power supply for a vast number of customers, it is necessary to perform multivariate testing and critical analyses of operating conditions of a power system. Currently available computer programs for simulation of the dynamic states of power systems use unreliable parameters of mathematical models of some power system elements, such as generating units and their regulation systems (synchronous generators, excitation systems, turbines and their governors). Due to the lack of actual parameters, typical data published in scientific-technical studies are used, as well as unreliable parameters obtained from catalog and design data, delivered by the manufacturers of component elements of generating units for most of which the launching period dates back to the 1970s. The values of these parameters do not take into account the actual operating conditions of generating units, including changes of their properties caused by long-term operation, as well as numerous repairs and modernizations, not always documented carefully and reliably on the technical side.

The values of the parameters of generating unit mathematical models determined in such a way are approximate and in many cases, encumbered with errors. Such data can be used in approximate analyses of typical, but not critical operating conditions of power systems. Reliable simulation investigations of the Polish National Power System (PNPS) underlying the planning of its development, as well as the analysis of critical operating conditions should be made based on accurate parameters obtained from measurement estimation.

The goals of the research performed were:

- developing methods and tools aiding the process of measurement parameter estimation of mathematical models of

*e-mail: lukasz.majka@polsl.pl generating unit component elements, i.e. synchronous generators, excitation systems, turbines and their governors, based on specific measurement tests carried out in a power plant during the generating unit operation,

- performing calculations (measurement estimation) for selected generating units operating in the PNPS, with use of the most favorable algorithm.

\section{Mathematical description of generating unit elements}

A generating unit operating in Pątnów Power Plant - a steam turbine driving TWW-200 turbo generator, together with an electro-machine excitation system consisting of a three-phase induction exciter, a diode rectifier and a voltage regulator - was chosen as a representative of generating units operating in the PNPS.

The classical mathematical model of a synchronous generator expressed by reactances and time constants in the $\mathrm{d}$ and $\mathrm{q}$ axis, including saturation of the machine magnetic circuit, is a model representing the turbo generator installed in a power plant. This model was used for simulation calculations. The state and output equations of the generator model together with a detailed description are presented in $[1,2,3]$.

The model of the electro-machine excitation system installed in Pątnów Power Plant consists of three submodels: the model of the voltage regulator, the model of the exciter with an additional regulator and the model of the excitation voltage forming system (Fig. 1). In the schematic diagram in Fig. 1, the particular signals are denoted by: $V_{\mathrm{T}}$ - generator terminal (stator) voltage, $V_{\text {ref }}$ - regulator reference voltage, $V_{\text {rov }}-$ voltage regulator output voltage, $I_{\mathrm{fe}}$ - exciter excitation current, $I_{\mathrm{fd}}$ - generator excitation current, $F_{\mathrm{ex}}$ - function determining the operating range of the diode rectifier, $E_{\mathrm{fd}}-$ generator field voltage. 


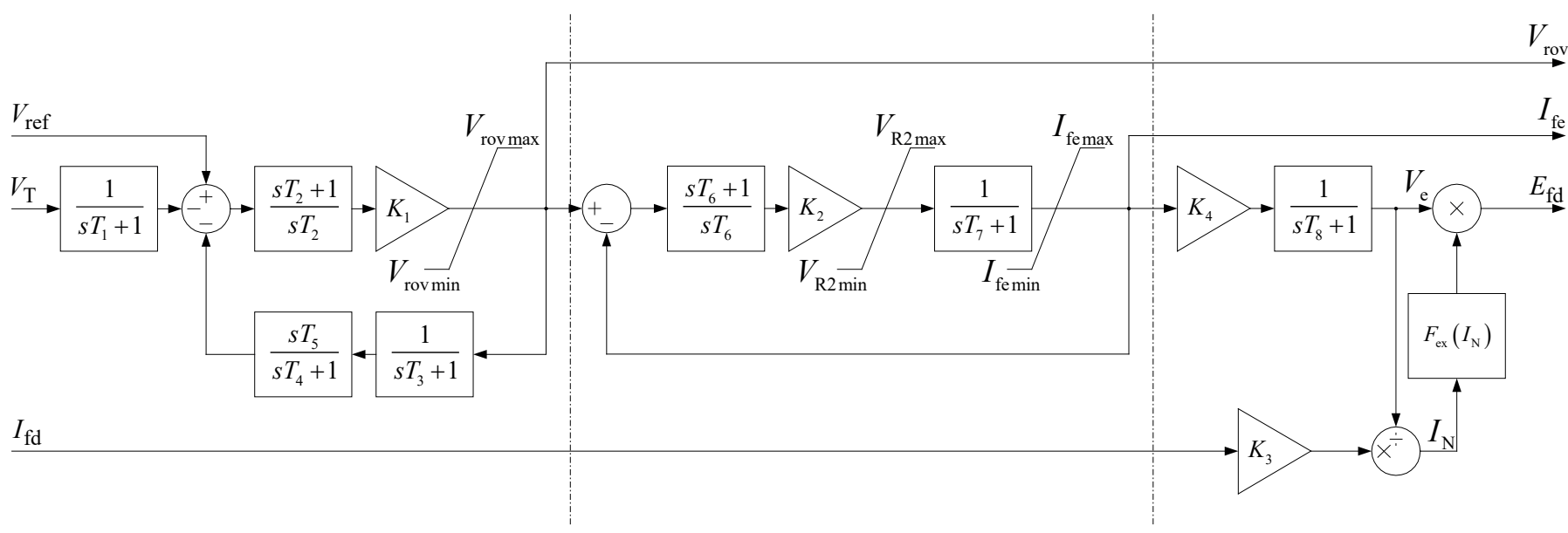

Fig. 1. Structural diagram and the input and output signals of the electro-machine excitation system model

For the investigations performed, the mathematical model standardized by the IEEE was assumed for the steam turbine with the governor $[3,4]$. In this model, the signals are denoted by: $\Delta \omega$ - signal of the angular speed deviation of the synchronous generator, $P_{0}$ - turbine reference power, $P_{\mathrm{d}}-$ power transmitted by the flow of steam at the inlet of the turbine, $P_{\mathrm{m}}$ - mechanical power of the turbine.

\section{Sensitivity analysis and definition of the objective function}

A proper defining of the objective function being minimized was one of the conditions for correct estimation. In this function, the dynamic waveforms of the output quantities of particular models, dependent on their parameters, had to intervene with appropriate weights. The sensitivity analysis was performed to determine the influence of changes in the values of particular model parameters on the dynamic waveforms - estimation signals (for appropriate test disturbances).

For calculations of the waveforms of the sensitivity of estimation signals, there was used the definition of half relative sensitivity, which connects absolute changes of the analyzed function with the relative changes of a parameter. Due to significant differences in the shape and value of the obtained signals (Fig. 2), special sensitivity factors for their unambiguous assessment were developed $[1,5,6]$. The selected sensitivity factor $S$ is defined as:

$$
S=\int_{t_{0}}^{t_{\mathrm{e}}}\left|K(t)_{x_{i}}^{y}\right|^{2} \mathrm{~d} t,
$$

where: $t_{0}, t_{\mathrm{e}}$ - time instant in which the analysis of the transient state of the model dynamic output waveform starts and ends, respectively.


Fig. 2. Example waveforms of the generator stator voltage sensitivity to the change of the value of selected parameters of the synchronous generator model in the d axis: $X_{\mathrm{d}}$ (the largest value) and $X$ " (the smallest value) at the step change in the voltage regulator reference voltage by $-5 \%$ 
Based on the factor (1), the objective function was defined. Next, it was assigned to the particular submodels (see Eqs. 2-8).

\section{Calculations}

Calculations of the parameters of particular components of the generating unit model were carried out based on the measurement and simulation dynamic waveforms of the selected quantities of the generating unit for appropriately chosen test disturbances.

The parameter estimation of particular submodels was an iterative process and involved an approximation of the dynamic waveforms obtained based on the test disturbances by the assumed models expressed by the searched parameters. The selected optimization algorithm, changing the parameters of the system models, brought the approximating waveforms closer to the approximated (measurement) ones. The calculation of the parameters of the models was realized as the minimization of the objective function expressed by the vector of deviations of approximating and approximated waveforms of the selected quantities (the so-called input signals of approximation) in an appropriate time interval and with a determined (given) accuracy $[1,7,8,9]$.

In the investigations, there was assumed the following sequence of parameter calculations of particular models of generating units elements (when applying the appropriate objective function minimized during calculations):

- the generator model:

- in the d axis:

$\varepsilon_{1}\left(\boldsymbol{P}_{1}\right)=\sum_{i=1}^{n}\left\{\left|I_{\mathrm{fd} i(\mathrm{~m})}-I_{\mathrm{fd} i(\mathrm{a})}\left(\boldsymbol{P}_{1}\right)\right|^{2}+\left|V_{\mathrm{T} i(\mathrm{~m})}-V_{\mathrm{T} i(\mathrm{a})}\left(\boldsymbol{P}_{1}\right)\right|^{2}\right\}$,

- in the q axis:

$\varepsilon_{2}\left(\boldsymbol{P}_{2}\right)=\sum_{i=1}^{n}\left|V_{\mathrm{T} i(\mathrm{~m})} \sin \left(\delta_{i(\mathrm{~m})}\right)-V_{\mathrm{T} i(\mathrm{a})}\left(\boldsymbol{P}_{2}\right) \sin \left(\delta_{i(\mathrm{a})}\left(\boldsymbol{P}_{2}\right)\right)\right|^{2}$,

- the excitation system model (in three substages):

- the voltage regulator mathematical model:

$$
\varepsilon_{3}\left(\boldsymbol{P}_{3}\right)=\sum_{i=1}^{n}\left|V_{\operatorname{rov} i(\mathrm{~m})}-V_{\operatorname{rov} i(\mathrm{a})}\left(\boldsymbol{P}_{3}\right)\right|^{2},
$$

- the mathematical model of the exciter and an additional regulator:

$$
\varepsilon_{4}\left(\boldsymbol{P}_{4}\right)=\sum_{i=1}^{n}\left|I_{\mathrm{fe} i(\mathrm{~m})}-I_{\mathrm{fe} i(\mathrm{a})}\left(\boldsymbol{P}_{4}\right)\right|^{2},
$$

- the mathematical model of the field voltage forming system:

$$
\varepsilon_{5}\left(\boldsymbol{P}_{5}\right)=\sum_{i=1}^{n}\left|E_{\mathrm{fd} i(\mathrm{~m})}-E_{\mathrm{fd} i(\mathrm{a})}\left(\boldsymbol{P}_{5}\right)\right|^{2},
$$

- the turbine mathematical model (in two substages):

- the mathematical model of the turbine speed controller:

$$
\varepsilon_{6}\left(\boldsymbol{P}_{6}\right)=\sum_{i=1}^{n}\left|P_{\mathrm{d} i(\mathrm{~m})}-P_{\mathrm{d} i(\mathrm{a})}\left(\boldsymbol{P}_{6}\right)\right|^{2},
$$

- the turbine mathematical model:

$$
\varepsilon_{7}\left(\boldsymbol{P}_{7}\right)=\sum_{i=1}^{n}\left|P_{\mathrm{m} i(\mathrm{~m})}-P_{\mathrm{m} i(\mathrm{a})}\left(\boldsymbol{P}_{7}\right)\right|^{2},
$$

where: $I_{\mathrm{fd} i}, V_{\mathrm{T} i}, \delta_{i}, V_{\mathrm{rovi}}, I_{\mathrm{fe} i}, E_{\mathrm{fd} i}, P_{\mathrm{m} i}, P_{\mathrm{d} i}-$ instantaneous values of the generator excitation current, stator voltage, generator power angle, voltage regulator output voltage, exciter excitation current, generator field voltage, mechanical power and the power transmitted by the flow of steam at the turbine inlet, respectively, $n$ - number of the measurement points taken into account, $\varepsilon\left(\boldsymbol{P}_{1-7}\right), \boldsymbol{P}_{1-7}-$ values of the errors and the vectors of the searched parameters in particular stages of calculations. The approximating quantities are non-explicit functions of the vector $\boldsymbol{P}$ whose elements are the searched parameters of the models of the generating unit elements. The index $m$ denotes the measured values, whereas the index a, the approximating ones.

\section{The algorithm used in the estimation process}

The minimization of the defined objective function was performed numerically with the use of a hybrid algorithm $[10,11]$, being the combination of genetic and hybrid algorithms. Both algorithms were implemented in Matlab (Genetic Algorithm and Direct Search Toolbox and Optimization Toolbox) [12]. Such a serial connection of genetic and gradient algorithms eliminates the basic drawbacks of both optimization methods. The use of a genetic algorithm in the first stage of searching the minimum of the objective function eliminates the problem of precise determination of the starting point [13, 14], whereas a gradient algorithm used in the second stage converges much faster towards the searched extremum [15].

\section{Filtration of the measured waveforms}

The dynamic waveforms of selected electrical quantities of the generating unit measured in the power plant in transient states were strongly disturbed. They were recorded at high sampling rate $\left(f_{\mathrm{m}}=3200 \mathrm{~Hz}\right)$. Disturbances in signals were the result of the measuring environment - the presence of machines (rotating machines and transformers) and electrical devices (coils, drives, high current paths), as well as converter systems (diodes and thyristors). The selected sampling frequency of the recorded signal was to represent the variability of the recorded signals as accurate as possible. Then, it was adapted to the sampling frequency of the signal used in simulations $\left(f_{\mathrm{s}}=400 \mathrm{~Hz}\right)$. This frequency resulted from the analyzed operating conditions of the generating unit (dynamics, duration of the transient state) and the optimal integration step determined experimentally 
( $\Delta t=2.5 \mathrm{~ms}$ ), which ensured the required ratio of the accuracy to the computational efficiency.

The analysis of the measurement signal with use of the short time (windowed) Fourier transform (STFT) showed the necessity of applying a low-pass filter. Finite impulse response filters (FIR) were chosen from the available digital filters [16]. Zero-phase filtering consisting in connecting two identical filters FIR in the way described in $[1,17]$ was used to eliminate a group delay introduced by the designed filter. After the FTT analysis, the parameters of the designed filters were individually selected for the recorded measurement waveforms. The example result of zero-phase filtering of the measurement waveform is shown in Fig. 3.



Fig. 3. Example waveform of the generator excitation current at the step change in the voltage regulator reference voltage by $+5 \%$ before and after filtration

\section{Exemplary calculations based on the measured and simulated waveforms}

The measurement parameter estimation of the mathematical model of the generating unit operating in the PNPS was performed based on the dynamic waveforms obtained from measurements in generating unit No. 3 of Pątnów Power Plant.

A generator whose ratings are $S_{\mathrm{n}}=270 \mathrm{MV} \cdot \mathrm{A}, V_{\mathrm{Tn}}=15.75 \mathrm{kV}$, $\cos \varphi_{\mathrm{n}}=0.85$ is driven by a $13 \mathrm{~K} 215$ steam turbine. The generator cooperates with an electro-machine excitation system consisting of a WGT-2700-500 three-phase induction exciter, an ETP 1500/1000D diode rectifier and an ETEF - 200C voltage regulator. This excitation system was designed and launched by the Energotest Gdańsk company [11]. The voltage regulator PI contains blocks of digitally adjustable parameters and an output IGBT-based amplifier.

7.1 Parameter estimation results for the synchronous generator mathematical model. The dynamic measurement waveforms of the field voltage (input signal) as well as the output signals: the waveforms of the excitation current and generator stator voltage (Fig. 4a) included in the objective function (2) were used for estimation of electromagnetic parameters (reactances and time constants) of the assumed generator model in the $d$ axis. Those dynamic waveforms were recorded for the following disturbances:

- opening the main switch causing generator load rejection in the $\mathrm{d}$ axis at $P_{0}=0, Q_{0}=0.3986$ (in relative units),

- step change of the voltage regulator reference voltage by $+5 \%$ and $-5 \%$ under the synchronous generator no-load conditions $\left(P_{0}=0, Q_{0}=0\right)$.

a)



b)



Fig. 4. Input and output signals of the synchronous generator model in the $\mathrm{d}$ and $\mathrm{q}$ axis

During the measurements, the generator operated with automatic regulation in the excitation system. The nonlinear measurement no-load characteristic of the generator was taken into account in the calculations. The input and output estimation signals for the selected disturbance are shown in Fig. 5.

The simulation dynamic waveforms (due to the lack of measurement ones) were used for the parameter estimation of the generator model in the $\mathrm{q}$ axis. Load rejection in the $\mathrm{q}$ axis was the test disturbance. In the calculations, the following initial values of the generator load were assumed: $P_{0}=0.2$ and $Q_{0}=-0.0837$ (in relative units). The dynamic waveforms of the generator field voltage and the turbine mechanical power were the input signals at that stage. In the objective function (3), there were included the output signals: the dynamic waveforms of the stator voltage and the power angle of the generator (Fig. 4b). Table 1 presents the results obtained in both stages.

7.2 Parameter estimation results for the electro-machine excitation system mathematical model. For the parameter estimation of the electro-machine excitation system model, there were used the dynamic measurement waveforms of the follow- 




b)



c)

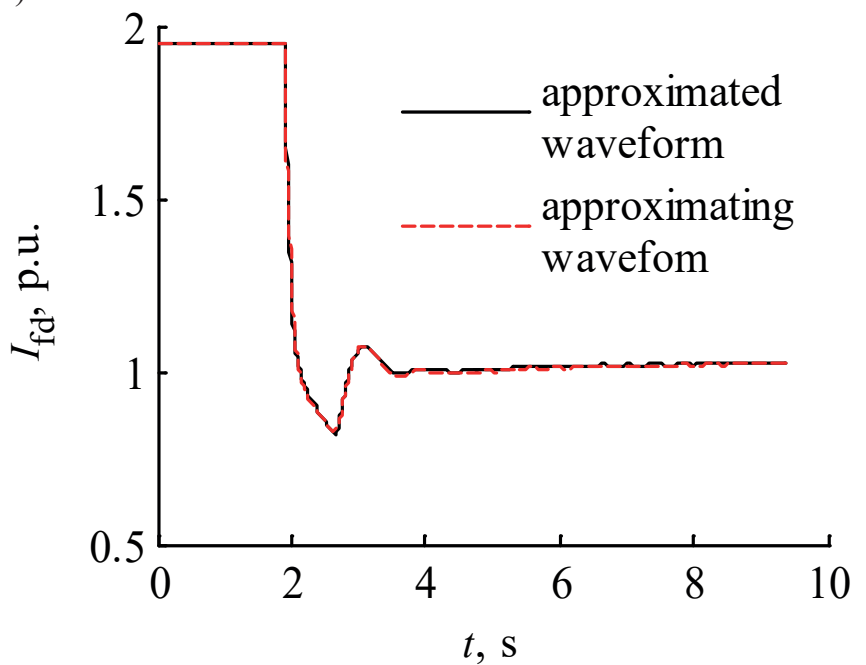

Fig. 5. Measurement waveforms: the input signal - generator field voltage (a) and the estimation output signals: generator stator voltage (b) and generator excitation current (c) at load rejection in the $\mathrm{d}$ axis ing electrical quantities of the generating unit: the generator stator voltage, the reference and output voltage of the voltage regulator, the exciter excitation current, the excitation current and field voltage of the generator. The disturbances considered were the same, as those for the parameter estimation of the generator model in the $\mathrm{d}$ axis.

To improve the efficiency of parameter calculations, the parameter estimation process was divided into three substages in which separate calculations were carried out.

In the first substage, there were determined the following parameters of the voltage regulator model (Fig. 1): the gain $K_{1}$ and the time constants $T_{1-5}$. The values of these parameters are known - they are digital settings of the regulator adjusted by operators at the stage of launching a generating unit. Their estimation made it possible to verify the assumed calculation method and the measurement accuracy. Minimization of the objective function (4) occurred, including the output signal, i.e. the waveforms of the voltage regulator output voltage recorded at the test disturbances. The recorded dynamic waveforms of the generator stator voltage and the voltage regulator reference voltage were the input estimation signals. Fig. 6 shows the example of input and output estimation signals for the selected disturbance.

a)

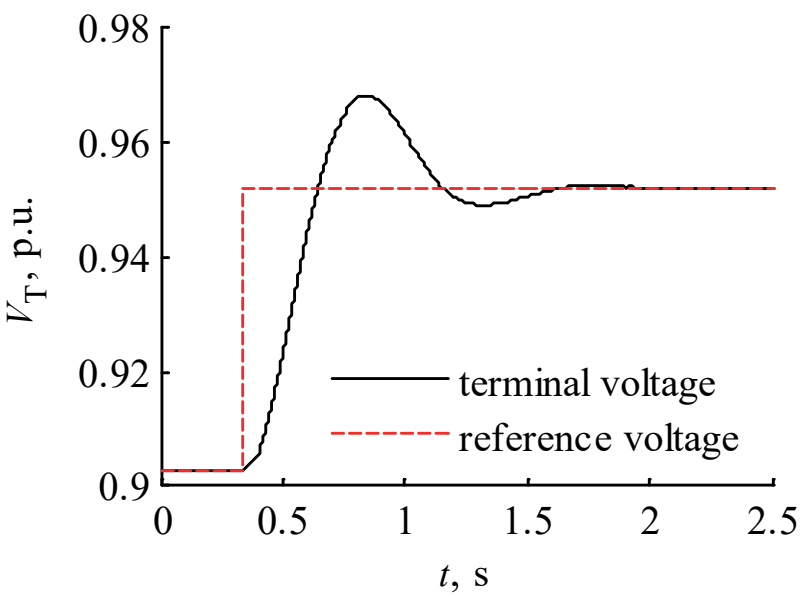

b)

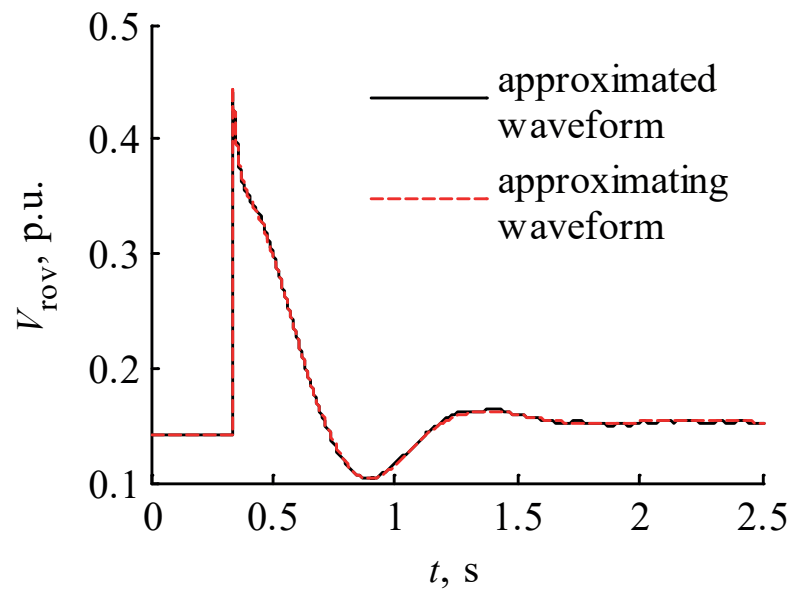

Fig. 6. Measurement waveforms - the input signals: generator stator voltage and voltage regulator reference voltage (a) and the output signal of estimation: voltage regulator output voltage (b) at the step change in the voltage regulator reference voltage by $+5 \%$ 
In the second substage, the following parameters of the mathematical model of the additional regulator and the exciter were determined (Fig. 1): the gain $K_{2}$ and the time constants $T_{6}$ and $T_{7}$. Minimization of the objective function occurred (5), including the output signal, i.e. the waveforms of the exciter excitation current recorded at the test disturbances. At that substage of calculations, the waveforms of the voltage regulator output voltage were the input estimation signal. Fig. 7 shows the example dynamic waveforms of the exciter excitation current.

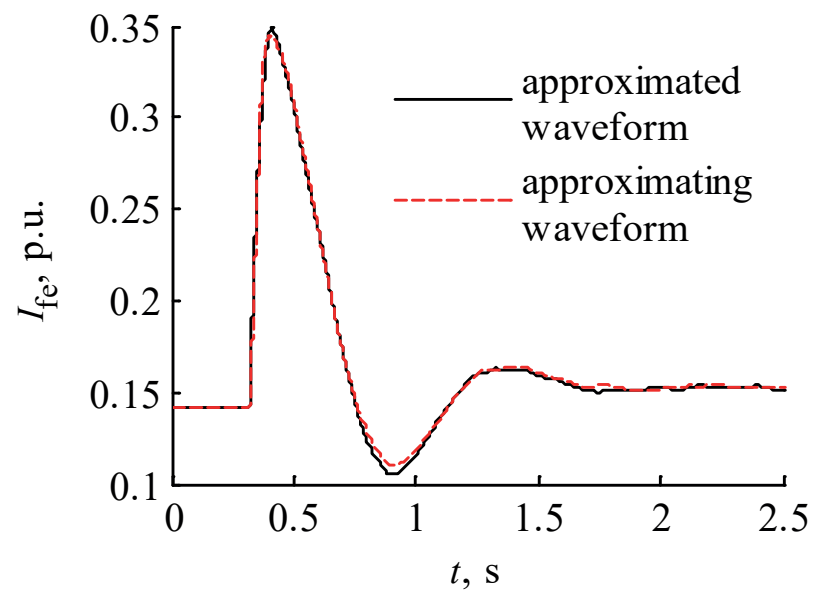

Fig. 7. Measurement waveforms of the output signal of estimation: the exciter excitation current at the step change in the voltage regulator reference voltage by $+5 \%$

In the third substage, there were determined the following parameters of the mathematical model of the field voltage forming system (Fig. 1): the gains $K_{3}$ and $K_{4}$ and the time constant $T_{8}$. Minimization of the objective function occurred (6), including the output signal, i.e. the dynamic waveforms of the generator field voltage recorded at the test disturbances. At that substage, the approximating waveforms were obtained based on two input signals: the dynamic waveforms of the exciter excitation current and the generator excitation current. Fig. 8 shows the example input and output estimation signals for the selected disturbance. Table 2 presents the calculation results for all the substages.

a)



b)

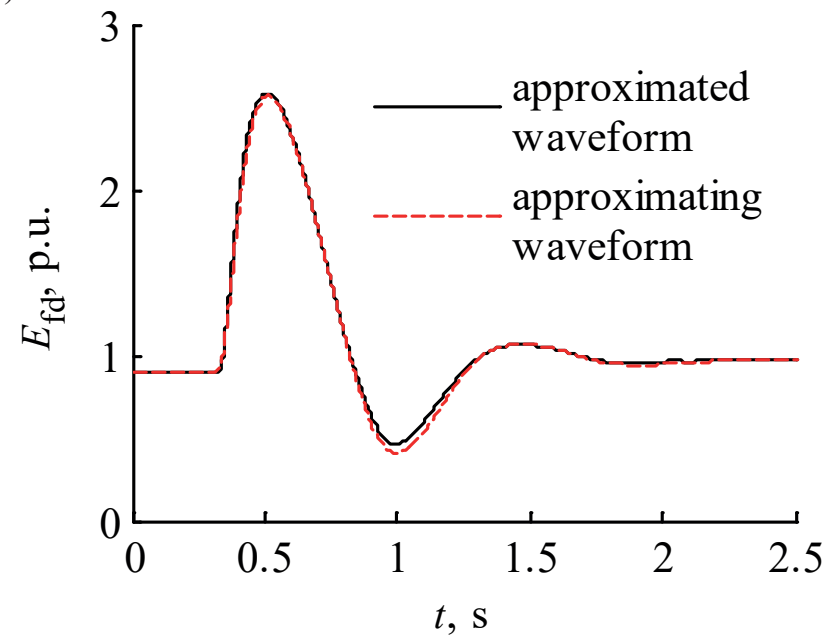

Fig. 8. Measurement waveforms: the input signal - generator excitation current (a) and the output signal of estimation - generator field voltage (b) at the step change in the voltage regulator reference voltage by $+5 \%$

7.3 Parameter estimation results for the mathematical model of the steam turbine with its governor. The simulation dynamic waveforms (due to the lack of measurement ones) were used for the parameter estimation of the model of the turbine with its governor. The load rejection in the $\mathrm{q}$ axis was the disturbance considered. In the calculations, there were assumed the following initial values of the generator load: $P_{0}=0.2$ and $Q_{0}=-0.0898$ (in relative units).

The parameter estimation of the turbine with its governor was performed in two substages. The model included two submodels: the turbine model and the turbine governor model (Fig. 9), for which the calculations were carried out separately.

Angular Speed Governor Steam Turbine

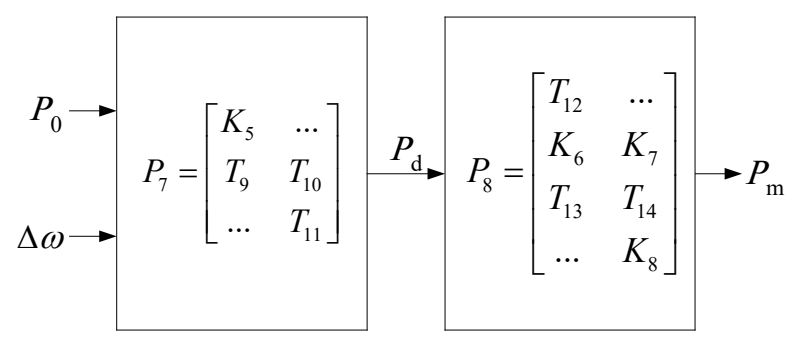

Fig. 9. Input and output signals of the steam turbine model

The gain $K_{5}$ and the time constants $T_{9-11}$ were determined in the first substage. There was minimization of the objective function (7), including the dynamic waveforms of the power transmitted by the flow of steam at the turbine inlet (output signal). The dynamic waveforms of the deviation of the generator angular speed and the turbine reference power were the input signals of the submodel.

In the second substage, there were determined the gains $K_{6-8}$ and the time constants $T_{12-14}$. The waveforms of the turbine 
mechanical power (output signal) were included in the objective function (8). The calculation results for both substages are presented in Table 3.

Table 1

The results of parameter estimation of the synchronous generator model in the $\mathrm{d}$ and $\mathrm{q}$ axis

\begin{tabular}{|c|c|c|c|c|c|c|}
\hline \multicolumn{7}{|c|}{ Parameters in the $d$ axis of the model } \\
\hline$T_{\mathrm{d} 0}$ & $T_{\mathrm{d} 0}^{\prime \prime}$ & $X_{\mathrm{d}}$ & $X_{\mathrm{d}}^{\prime}$ & $X^{\prime \prime}{ }_{\mathrm{d}}$ & $S_{10}$ & $S_{12}$ \\
\hline$[\mathrm{s}]$ & {$[\mathrm{s}]$} & {$[-]$} & {$[-]$} & {$[-]$} & {$[-]$} & {$[-]$} \\
\hline 5.9301 & 0.0900 & 1.9090 & 0.2000 & 0.1635 & 0.0200 & 0.4700 \\
\hline \multicolumn{7}{|c|}{ Number of generations: $50, \varepsilon(\boldsymbol{P})=6.32$} \\
\hline \multicolumn{7}{|c|}{ Number of iterations: $13, \varepsilon(\boldsymbol{P})=4.72 \mathrm{e}-2$} \\
\hline \multicolumn{7}{|c|}{ Parameters in the $q$ axis of the model } \\
\hline & & $T_{\mathrm{q} 0}^{\prime}$ & $T_{\mathrm{q} 0}^{\prime \prime}$ & $X_{\mathrm{q}}$ & & $X_{\mathrm{q}}$ \\
\hline & & {$[\mathrm{s}]$} & {$[\mathrm{s}]$} & {$[-$.} & & {$[-]$} \\
\hline Calc & lated & 0.6701 & 0.0500 & 1.710 & & 0.4399 \\
\hline & & 0.6700 & 0.0500 & 1.71( & & 0.4400 \\
\hline Relativ & error $\%$ & 0.0149 & 0.0000 & 0.005 & & -0.0227 \\
\hline \multicolumn{7}{|c|}{ Number of generations: $50, \varepsilon(\boldsymbol{P})=5.22$} \\
\hline \multicolumn{7}{|c|}{ Number of iterations: $5, \varepsilon(\boldsymbol{P})=2.93 \mathrm{e}-9$} \\
\hline
\end{tabular}

\section{Concluding remarks}

The investigations performed allow for drawing the following conclusions:

- The developed mathematical model of the generating unit, despite the adoption of the inevitable simplifying assumptions, represents well the phenomena and processes occurring in the corresponding real object.

- Division of the generating unit mathematical model into the following elements: the synchronous generator model, the model of the excitation system with the voltage regulator and the model of the turbine with its governor enabled the separate estimation of the parameters of these models. This limited the number of the parameters determined at the same time, increasing the efficiency and accuracy of the calculations made.

- The developed mathematical models of the generator in the $\mathrm{d}$ axis and the electro-machine excitation system well represent the devices installed in power plants of the PNPS. This is confirmed by the calculations carried out with use of measurement waveforms.

- The generator parameters in the $\mathrm{d}$ axis calculated based on the measurement parameters differ from the catalog parameters. So the use of generator catalog parameters when simulating transient states in the PNPS results in significant errors and inaccuracy of calculations.

Table 2

The results of parameter estimation of the electromachine excitation system

\begin{tabular}{|c|c|c|c|c|c|}
\hline \multicolumn{6}{|c|}{ Parameters of the voltage regulator system model } \\
\hline$T_{1}$ & $T_{2}$ & $K_{1}$ & $T_{3}$ & $T_{4}$ & $T_{5}$ \\
\hline$[\mathrm{s}]$ & {$[\mathrm{s}]$} & {$[-]$} & {$[\mathrm{s}]$} & {$[\mathrm{s}]$} & [s ] \\
\hline 0.0205 & 3.0750 & 6.0235 & 0.0512 & 0.2562 & 0.0244 \\
\hline \multicolumn{6}{|c|}{ Number of generations: $50, \varepsilon(\boldsymbol{P})=9.12$} \\
\hline \multicolumn{6}{|c|}{ Number of iterations: $5, \varepsilon(\boldsymbol{P})=1.21 \mathrm{e}-3$} \\
\hline \multicolumn{3}{|c|}{ Parameters of the additional regulator and exciter model } & \multicolumn{3}{|c|}{ Parameters of the field voltage forming system model } \\
\hline$T_{6}$ & $K_{2}$ & $T_{7}$ & $K_{3}$ & $T_{8}$ & $K_{4}$ \\
\hline [s ] & {$[-]$} & [s ] & {$[-]$} & [s ] & {$[-]$} \\
\hline 0.4962 & 10.1000 & 0.1150 & 1.1350 & 0.0843 & 10.1975 \\
\hline \multicolumn{3}{|c|}{ Number of generations: $50, \varepsilon(\boldsymbol{P})=2.15$} & \multicolumn{3}{|c|}{ Number of generations: $50, \varepsilon(\boldsymbol{P})=9.56$} \\
\hline \multicolumn{3}{|c|}{ Number of iterations: $5, \varepsilon(\boldsymbol{P})=6.69 \mathrm{e}-2$} & \multicolumn{3}{|c|}{ Number of iterations: $5, \varepsilon(\boldsymbol{P})=3.62 \mathrm{e}-3$} \\
\hline
\end{tabular}

Table 3

The results of parameter estimation of the model of the steam turbine and its governor (simulation waveforms) at load rejection in the $\mathrm{q}$ axis

\begin{tabular}{|c|c|c|c|c|c|c|c|c|c|c|}
\hline & \multicolumn{4}{|c|}{ Parameters of the governor model } & \multicolumn{6}{|c|}{ Parameters of the steam turbine model } \\
\hline & $K_{6}$ & $T_{8}$ & $T_{9}$ & $T_{10}$ & $T_{11}$ & $K_{7}$ & $T_{12}$ & $K_{8}$ & $T_{13}$ & $K_{9}$ \\
\hline & {$[-]$} & [s ] & [s] & [s] & [s] & {$[-]$} & [s] & {$[-]$} & [s] & {$[-]$} \\
\hline Calculated & 11.9996 & 0.4499 & 0.0201 & 0.0701 & 0.0600 & 0.5001 & 4.0000 & 0.1972 & 0.2989 & 0.3027 \\
\hline True & 12.0000 & 0.4500 & 0.0200 & 0.0700 & 0.0600 & 0.5000 & 4.0000 & 0.2000 & 0.3000 & 0.3000 \\
\hline \multirow[t]{3}{*}{ Relative error \% } & -0.0033 & -0.0222 & 0.5000 & 0.1429 & 0.0000 & 0.0200 & 0.0000 & -1.4000 & -0.3667 & 0.9000 \\
\hline & \multicolumn{4}{|c|}{ Number of generations: $50, \varepsilon(\boldsymbol{P})=2.26 \mathrm{e}-1$} & \multicolumn{6}{|c|}{ Number of generations: $50, \varepsilon(\boldsymbol{P})=1.42$} \\
\hline & \multicolumn{4}{|c|}{ Number of iterations: $4, \varepsilon(\boldsymbol{P})=8.59 \mathrm{e}-9$} & \multicolumn{6}{|c|}{ Number of iterations: $4, \varepsilon(\boldsymbol{P})=4.36 \mathrm{e}-9$} \\
\hline
\end{tabular}


- The use of the simulation waveforms for calculations made it possible to determine the parameters of the mathematical models of the generator in the $\mathrm{q}$ axis and the steam turbine with its governor despite the lack of measurement waveforms, as well as to analyze the efficiency of the selected calculation method and the optimization algorithm.

- The use of the hybrid algorithm for calculations proved advantageous. The series connection of the genetic and gradient algorithms highlighted the advantages and eliminated the main drawbacks of both optimization methods (elimination of restrictions on the starting point, ensuring the required accuracy and significant shortening of the calculation time).

- In order to obtain accurate results, it is necessary to have reliable steady state measurements.

- The estimation process is more effective when accompanied by the analysis of the sensitivity of dynamic waveforms in the analyzed transient states to the change of parameters of particular models. The results of this analysis can be useful in choosing the appropriate modification of the objective function minimized in the parameter estimation of the models of particular elements of a generating unit.

- A larger number of disturbances included in the objective function (e.g. both a step change in the reference voltage by a constant value and load rejection in the $\mathrm{d}$ axis) results in an insignificant worsening of the approximation of a measurement waveform (greater value of the error). However, the parameter values calculated that way are more reliable than those calculated based only on the waveforms obtained for one selected disturbance.

\section{REFERENCES}

[1] S. Paszek, S. Berhausen, A. Boboń, Ł. Majka, A. Nocoń, M. Pasko, P. Pruski and T. Kraszewski, Measurement Estimation of Dynamic Parameters of Synchronous Generators and Excitation Systems Working in the National Power System, Silesian University of Technology Publishing House, Gliwice, 2008, (in Polish).

[2] S. Paszek and A. Nocoń, Optimisation and Polyoptimisation of Power System Stabilizer Parameters, LAMBERT Acedemic Publishing, Saarbrücken, 2014.

[3] Power Technologies, a Division of S\&W Consultants Inc., Program PSS/E Application Guide, Siemens Power Technologies Inc., 2002.
[4] IEEE Committee Report, "Dynamic Models for Steam and Hydro Turbines in Power System Studies", IEEE Transactions on Power Apparatus and Systems, Vol. PAS-92, No. 6, 1904-1915 (1973).

[5] T. Kraszewski, Ł. Majka, M. Pasko and S. Paszek, "Sensitivity Analysis of the Electromachine Excitation System Model", Proc. 9th International Conference Control of Power Systems CPS 2010, Tatranské Matliare, High Tatras, Slovak Republic, 29-30 (2010).

[6] A. Nocoń, M. Pasko and S. Paszek, "Sensitivity analysis including uncertainty of synchronous generator model parameter", Proc. 9th International Conference Control of Power Systems CPS 2010, Tatranské Matliare, High Tatras, Slovak Republic, 27-28 (2010).

[7] J.W. Feltes and L.T.G. Lima, "Validation of Dynamic Model Parameters for Stability Analysis: Industry Need, Current Practices and Future Trends", Power Engineering Society General Meeting IEEE 2003, Vol. 3, 1295-1301 (2003).

[8] S. Paszek, A. Boboń, J. Kudła, J. Białek and N. Abi-Samra, "Parameter Estimation of the Mathematical Model of a Generator, Excitation System and Turbine", Przeglad Elektrotechniczny, No. 11, 7-12 (2005).

[9] S. Berhausen and S. Paszek, "Parameter estimation of the model of a synchronous generator working in multi-machine power system", Przeglad Elektrotechniczny, No. 8, 192-197 (2011), (in Polish).

[10] A. Nocoń and S. Paszek, "Synthesis of generator voltage regulator when applying polyoptimisation", Bull. Pol. Ac.: Tech. 55 (1), 43-48 (2007).

[11] Ł. Majka and S. Paszek, "Use of hybrid algorithm for estimation of generating unit mathematical model parameters", Przegląd Elektrotechniczny, No. 8, 70-76 (2010), (in Polish).

[12] Online Documentation for MathWorks Products, 2014, (www. mathworks.com).

[13] S.N. Sivanandam and S.N. Deepa, Introduction to Genetic Algorithms, Springer-Verlag, Berlin Heidelberg, 2008.

[14] S. Paszek, A. Nocoń, "Parameter polyoptimization of PSS2A power system stabilizers operating in a multi-machine power system including the uncertainty of model parameters", Elsevier, Applied Mathematics and Computation 267 (http://dx.doi. org/10.1016/j.amc.2014.12.013), 750-757 (2015).

[15] P. Pruski and S. Paszek, "Assessment of Polish Power System angular stability based on analysis of different disturbance waveforms", Bull. Pol. Ac.: Tech. 63 (2), 435-441 (2015).

[16] A. Oppenheim and R. Schafer, Discrete-time signal processing. $2^{\text {nd }}$ Edition, Prentice Hall, Upper Saddle River, 1999.

[17] S. Berhausen and S. Paszek, "Use of the finite element method for parameter estimation of the circuit model of a high power synchronous generator", Bull. Pol. Ac.: Tech., 63 (3), 575-582 (2015). 